\title{
Preparation and Characterization of PMMA and its Derivative via RAFT Technique in the Presence of Disulfide as a Source of Chain Transfer Agent
}

\author{
Juan Li, Ting-Ting Jiang, Jiang-Nan Shen and Hui-Min Ruan \\ College of Chemical Engineering and Materials of Zhejiang University of Technology Hangzhou, 310014, \\ China
}

\begin{abstract}
Poly(methyl methacrylate) (PMMA) were synthesized by using chain transfer agents(CTA), S-1-Dodecyl-S'( $\alpha, \alpha^{\prime}$-dimethyl-a-acetic acid) trithiocarbonate (MTTCD), S, $S^{\prime}$-bis (2-hydroxyethyl-2'-dimethylacrylate) trithiocarbonate (BDATC), 2-cyanoprop-2-yl dithiobenzoate (CPDB) respectively, through the reversible addition fragmentation chain transfer (RAFT) polymerization under a range of synthesis conditions. The results indicated that the structure of the endgroup of RAFT agents had significant effects on the ability to control polymerization. Compared with MTTCD and CPDB, BDATC can provide better control over the relative molecular mass, distribution and polymerization of PMMA. The derived well-controlled block copolymer PMMA-b-PDMAEMA and PMMA-b-PDMAEA were also successfully prepared by using $\mathrm{N}, \mathrm{N}$-dimethylaminoethy acrylate (DMAEA) or N, N-dimethylaminoethyl methacrylate (DMAEMA) as the second monomer. The chemical composition and structure of the products were characterized by FTIR, ${ }^{1} \mathrm{HNMR}, \mathrm{XRD}$ and DSC. $\mathrm{CO}_{2}$ and $\mathrm{N}_{2}$ permeation performance of the PMMA-b-PDMAEA/PS composite membranes were tested at different pressure. The results showed that the resulted composited membrane had a $\mathrm{CO}_{2}$ permeation rate of $3.68 \times 10^{-5} \mathrm{~cm}^{3}$ (STP) $\mathrm{cm}^{-2} \mathrm{~s}^{-1} \mathrm{cmHg}^{-1}$, a N permeation rate of $1.78 \times 10^{-7} \mathrm{~cm}^{3}$ (STP) $\mathrm{cm}^{-2} \mathrm{~s}^{-1} \mathrm{cmHg}^{-1}$ and an ideal $\mathrm{CO}_{2} / \mathrm{N}_{2}$ selectivity of 206.6 at a feed gas pressure of $7.6 \mathrm{cmHg}$ and $30^{\circ} \mathrm{C}$.
\end{abstract}

Keywords: Reversible addition fragmentation chain transfer (RAFT)polymerization, Disulfide compounds, Theoretical molecular weight, PMMA-b-PDMAEMA, PMMA- b-PDMAEA.

\section{INTRODUCTION}

Facilitated transport membranes for gas separation have attracted the attention of many researchers, due to their very high permselectivity compared with conventional polymeric membranes [1]. Moreover, they involve a carrier mediated transport in addition to permeate physical dissolution and diffusion. In recent years, fixed carrier membranes for $\mathrm{CO}_{2}$ separation with facilitated transport groups of amine moieties have been investigated extensively [2-4]. Kima et al. [5] developed a new cation-exchange polysaccharide membrane containing a diamine complexing agent for $\mathrm{CO}_{2}$ facilitated transport. The effect of amino acids such as asparagine, valine, glutamic acid and glycine on silver ion activity as an olefin carrier in membrane consisting of silver ions dissolved in poly(2-ethyl-2oxazoline) (POZ) has been investigated [6]. Novel fixed carrier composite membranes were developed by interfacial polymerization with water-soluble trimethylene tetramine (TETA) and hexane-soluble trimesoyl chloride (TMC) on polyethersulfone (PES) supports [7]. Wang et al. [8-10] prepared a series of facilitated transport membranes through various methods. For example, a membrane material containing facilitated transport groups for carbon

\footnotetext{
*Address corresponding to this author at the College of Chemical Engineering and Materials of Zhejiang University of Technology Hangzhou, 310014, China: Tel: +86 571 88320711; Fax: +86 571 88320711; E-mail: shenjn@zjut.edu.cn
}

dioxide through the hydrolysis of polyvinylpyrrolidone (PVP) obtained by radical polymerization. His group also first reported $\mathrm{N}$-vinyl- $\mathrm{y}$-sodium aminobutyratesodium acrylate copolymer (VSA-SA) using free radical polymerization. Shen [11] prepared a facilitated transport membrane based on the solid polymer electrolytes of poly(vinyl alcohol)- $\mathrm{Co}^{2+}\left(\mathrm{PVA}^{2+\mathrm{Co}^{2+}}\right)$ blends. Poly(acrylic acid) (PAA)/poly(vinyl alcohol) (PVA) membrane was prepared for the facilitated transport of $\mathrm{CO}_{2}$. The carrier of $\mathrm{CO}_{2}$ was monoprotonated ethylenedi-amine which was introduced in the membrane by ion exchange [12]. However, RAFT process to prepare facilitated transport membrane materials containing groups of amine moieties has seldom been reported in the past work.

The chemical versatility by controlling the agents during the RAFT process makes RAFT-based procedures highly attractive for the preparation of welldefined polymers with specific polymer architectures [13-15]. The first reversible addition fragmentation chain transfer (RAFT) polymerization was reported by Rizzardo in 1998 [16]. Up to now, the RAFT polymerization has been successfully applied to many monomers including functional and water-soluble monomers [17-19]. RAFT polymerization consists in the introduction of a small amount of thiocarbonylthio compound as the chain transfer agent (CTA) into a classical free radical polymerization system. RAFT agents are mainly dithioester, 2, 3-xanthate, 
trithiocarbonate [20] and dithiocarbamate [21-24]. Rizzado and other researchers [25-27] have reported that the RAFT polymerization under a particular set of reaction conditions depending on the nature of the $Z$ and $R$ groups of RAFT agents. With the appropriate choice of CTA/monomer system and reaction conditions, the well-defined polymers with predictable molecular weights, low polydispersity indices (PDIs), and precisely controlled architectures can be produced [28]. The mechanism of the RAFT process is shown in Scheme 1. RAFT polymerization comprises five steps: initiation, transfer, reinitiation, chain equilibration, termination. Initiation and termination occur as in conventional radical polymerization. In the early stages of the polymerization, addition of a propagating radical $\left(P_{n} \cdot\right)$ to the thiocarbonylthio compound $[R S C(Z)=S(1)]$ followed by fragmentation of the intermediate radical provides a polymeric thiocarbonylthio compound $\left[P_{n} S C(Z)=S(3)\right]$ and a new radical $(R \cdot)$. Reaction of this radical $(R \cdot)$ with monomer forms a new propagating $\operatorname{radical}\left(P_{m} \cdot\right)$. Rapid equilibrium between the active propagating radicals and the dormant polymeric thiocarbonylthio compounds(3) provides equal probability for all chains to grow and allows for the production of narrow polydispersity polymers. Block copolymerization of a functional monomer with an existing polymer offers an effective approach to incorporating new properties into the parent polymer, while retaining the desirable properties of the parent polymer. MMA, DMAEMA and DMAEA are potential monomers that can be used to prepare membranes for $\mathrm{CO}_{2}$ separation.

In this article, the controlled/living radical polymerization of MMA with MTTCD, BDATC, CPDB
(Scheme 2) as a RAFT agent and AIBN as an initiator in a 1,4-dixoane solution was reported. Well-defined PMMA homopolymers, PMMA-b-PDMAEMA and PMMA-b-PDMAEA block polymers were successfully synthesized. The chemical composition and structure were analyzed by FTIR, ${ }^{1} \mathrm{HNMR}, \mathrm{XRD}$ and DSC, the molecular weight and polydispersity index were analyzed by GPC. The effects of AIBN/CTA dosage and monomer/CTA dosage on the polymerization kinetics were discussed.

\section{EXPERIMENTAL}

\subsection{Materials}

MMA, DMAEMA and DMAEA were purified by being reduced pressure to remove inhibitor. These chemicals (analytical reagents) were purchased from Shanghai Chemical Reagent Co., Ltd., China. 1, 4-dioxane was distilled from $\mathrm{LiAlH}_{4} \quad\left(110{ }^{\circ} \mathrm{C}\right) . \quad 2, \quad 2$ 2'-Azobis(isobutyronitrile) (AIBN) (Fluka, $98 \%$ ) was purified by re-crystallization from ethanol at $40{ }^{\circ} \mathrm{C}$, dried at room temperature in vacuum, and stored in a refrigerator at $-15{ }^{\circ} \mathrm{C}$. All other chemicals used in the experiments were commercially analytical grade. Disulfide compounds were prepared according to the method described in documents. Their molecular structures were shown in Scheme 2. MTTCD was synthesized according to the methods reported in the literature [29]. ${ }^{1} \mathrm{HNMR}\left(\mathrm{CDCl}_{3}\right): 1.94 \mathrm{ppm}(\mathrm{s}, 6 \mathrm{H}, \mathrm{m}$ $\left.\mathrm{C}\left(\mathrm{CH}_{3}\right)_{2}\right), 7.40 \mathrm{ppm}(\mathrm{m}, 2 \mathrm{H}, \mathrm{m}-\mathrm{ArH}), 7.58 \mathrm{ppm}(\mathrm{m}, 1 \mathrm{H}$, $\mathrm{m}-\mathrm{ArH}), 7.91 \mathrm{ppm}(\mathrm{m}, 1 \mathrm{H}, 0-\mathrm{ArH})$. BDATC was synthesized according to the methods reported in the literature [29], $\quad \mathrm{IR}\left(\mathrm{KBr}, \mathrm{cm}^{-1}\right): 1700,1060$;

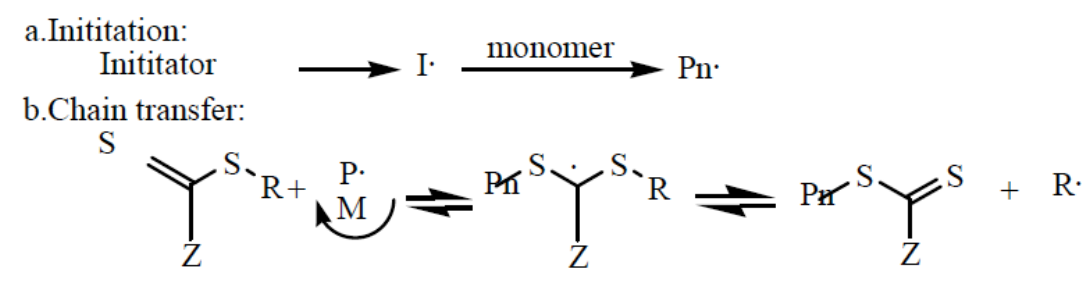

c.Reinitiation:

$$
\mathrm{R} \cdot \stackrel{\text { monomer }}{\longrightarrow} \mathrm{Pm} \text {. }
$$

d. Chain equilibration:

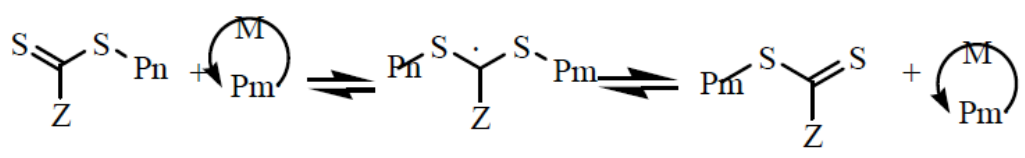

e.Termination:

$\mathrm{Pm} \cdot+\mathrm{Pn} \cdot \longrightarrow$ dead polymer

Scheme 1: Mechanism of the RAFT process. 
${ }^{1} \mathrm{HNMR}\left(\mathrm{CDCl}_{3}, \delta\right): 1.59,11.0$. CPDB was synthesized according to the methods reported in the literature [30], ${ }^{1} \mathrm{HNMR}\left(\mathrm{CDCl}_{3}\right): 1.94 \mathrm{ppm}\left(\mathrm{s}, 6 \mathrm{H}, \mathrm{m}-\mathrm{C}\left(\mathrm{CH}_{3}\right)_{2}\right), 7.40$ ppm (m, 2H, m-ArH), 7.58 ppm (m, 1H, m -ArH), 7.91 ppm (m, 1H, o-ArH).

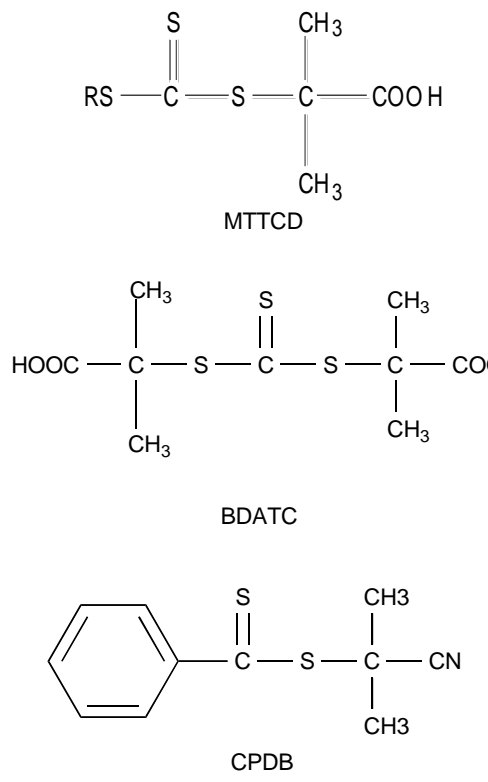

Scheme 2: Chemical structures of MTTCD, BDATC, CPDB.

The permeation testing set-up used were similar to reported previously. The effective area of the tested composite membrane is $19.6 \mathrm{~cm}^{2}$. The obtained membrane was tested by feed gas which was pure gas of $\mathrm{CO}_{2}$ and $\mathrm{N}_{2}$. The permeation rate of the gas was calculated from the flow rate of $\mathrm{H}_{2}$ which is the sweep gas and the integral area of the penetrate gas, $\mathrm{CO}_{2}$ and $\mathrm{N}_{2}$, from the gas chromatograph with a thermal conductivity detector. The permeation rate and the selectivity are given by $\mathrm{R}_{\mathrm{i}}=\mathrm{N}_{\mathrm{i}} / \Delta \mathrm{p}_{\mathrm{i}}, \mathrm{S}_{\mathrm{CO} 2 / \mathrm{N} 2}=R_{\mathrm{CO} 2} / R_{\mathrm{N} 2}$.

Where $\mathrm{N}_{\mathrm{i}}$ is the permeation flux of permeate gas, $\Delta \mathrm{p}_{\mathrm{i}}$ is the trans-membrane partial pressure difference. $\mathrm{R}_{\mathrm{CO} 2}, \mathrm{R}_{\mathrm{N} 2}$ are the permeation rate of $\mathrm{CO}_{2}$ and $\mathrm{N}_{2}$, respectively.

\subsection{Polymerization}

\subsubsection{RAFT Polymerization of MMA}

A typical polymerization procedure is as follows. Schlenk polymerization tubes were filled with MMA, AIBN, MTTCD or BDATC or CPDB, and 1, 4-dixoane were degassed by three freeze-pump-thaw cycles, then charged with nitrogen and sealed. The polymerization tubes were heated at $70{ }^{\circ} \mathrm{C}$ in a thermostated oil bath. After a predetermined time, the content was stopped by cooling the solution in ice water and diluted with THF.
The polymer solution was poured into a large excess of petroleum ether to precipitate PMMA homopolymer. The viscous polymer was dried under the condition of vacuum to a constant weight. The monomer conversions were determined gravimetrically. The molecular weights increased linearly with monomer conversion and were close to the theoretical molecular weights which were obtained from following equation:

$$
M_{n, t h}=M_{n, \text { Raft }}+\frac{[M M A]_{0} \cdot M_{0} \cdot x}{[R A F T]_{0}}
$$

where $[M M A]_{0}$ and $[R A F T]_{0}$ are the starting concentrations of the MMA and the RAFT agent, respectively, $x$ is the fractional conversion, and $M_{0}$ is the molar mass of the MMA. $M_{n, \text { raft }}$ is the molar mass of the RAFT agent.

\subsubsection{Polymerization of DMAEMA and DMAEA with PMMA-CTA as a Macro-RAFT Agent}

The RAFT polymerizations of DMAEMA and DMAEA were carried out with the same procedure mentioned previously. PMMA-CTA $(0.54 \mathrm{~g}, 0.01 \mathrm{mmol})$, DMAEMA $(0.78605 \mathrm{~g}, 500 \mathrm{mmol})$, and AIBN $(0.54 \mathrm{mg}$, $0.0033 \mathrm{mmol}$ ) were dissolved in 1,4-dioxane in a flask. The solution was degassed by three freeze-vacuumthaw cycles. The block copolymerization was carried out at $70{ }^{\circ} \mathrm{C}$ for $10 \mathrm{~h}$ and stopped by cooling the solution in iced water. The polymer solution was poured into a large excess of petroleum ether to precipitate PMMA-b-PDMAEMA block copolymer. The block polymer was dried under the condition of vacuum to a constant weight. The synthetic route for PMMA-bPDMAEMA in presence of CPDB is shown in Scheme 3.

From Scheme 3, we can see that firstly macromolecules chain transfer agents poly(methyl methacrylate) (PMMA-CTA) were synthesized through RAFT polymerization by using CPDB as the chain transfer agents and MMA as the first monomer. Then to demonstrate the living character of this polymerization system, PMMA chain was subsequently extended with DMAEMA to yield a block copolymer and lastly the derived well-controlled block copolymer PMMA-bPDMAEA were successfully prepared.

\subsection{Characterization}

The chemical structure of the PMMA, PMMA-bPDMAEMA and PMMA-b-PDMAEA polymer were studied by FT-IR spectroscopy on a Nicolet 6700 FT-IR spectrophotometer (Thermo, Inc., America), with the 


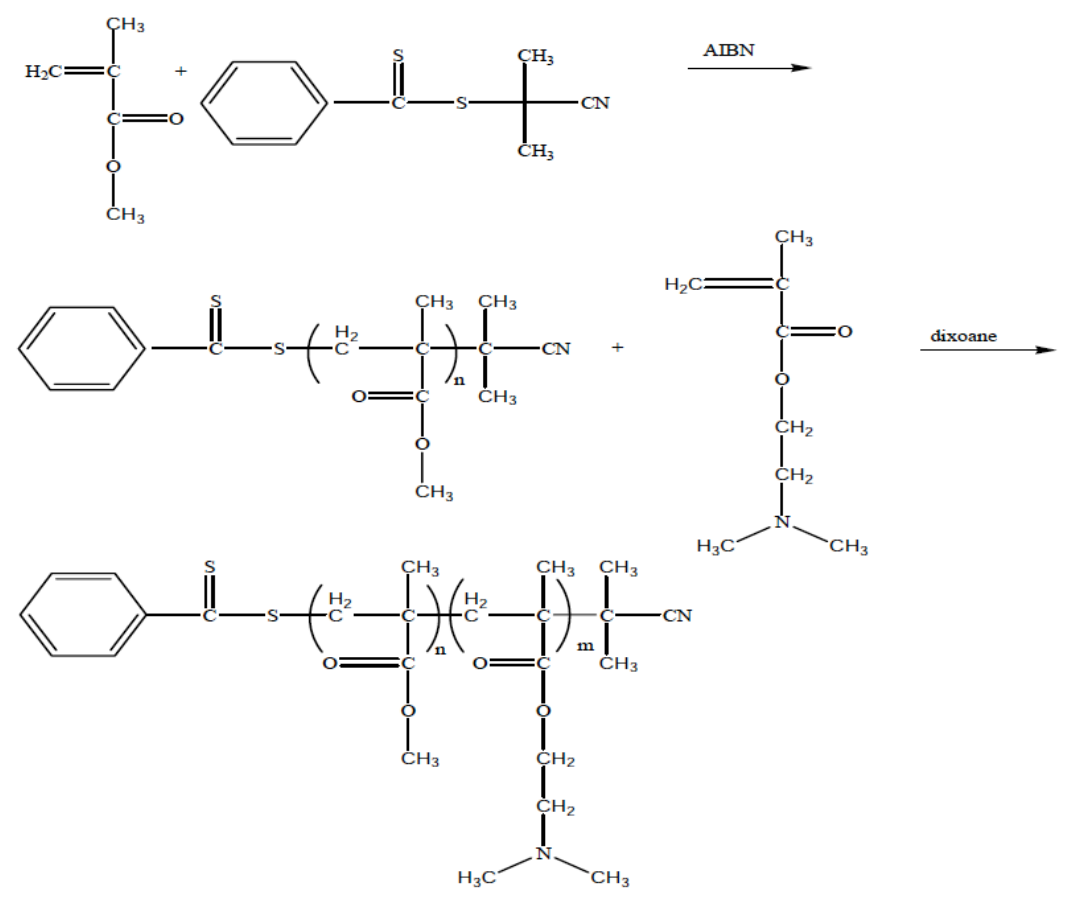

Scheme 3: The synthetic route for PMMA-b-PDMAEMA in presence of CPDB.

polymer samples dispersed in $\mathrm{KBr}$ pellets. The copolymer compositions were determined by NMR spectroscopy. ${ }^{1} \mathrm{HNMR}$ measurements were performed on a UNITY-plus $400 \mathrm{M}$ nuclear magnetic resonance spectrometer(Varian, Inc., America) using $\mathrm{CDCl}_{3}$ as the solvent. The thermal behavior was analyzed by differential scanning calorimetry on a NETZSCH DSC 200 (Netzsch, Inc., Germany). The DSC scanning was performed at a heating rate of $10{ }^{\circ} \mathrm{C} / \mathrm{min}$ under inert atmospheres. XRD was used to test the crystalline of the polymers on a $X^{\prime}$ pert Pro X-ray diffraction(PANalytical, Netherlands). The numberaverage molecular weight $\left(M_{n}\right)$, weight-average molecular weight $\left(M_{w}\right)$, and polydispersity $\left(M_{w} / M_{n}\right)$ of the polymers were estimated by gel permeation chromatograph (GPC)/size exclusion chromatography (SEC) at $30{ }^{\circ} \mathrm{C}$ with a Waters chromatography, Inc. (Milford) system equipped with an isocratic pump model 1525, a refractometer model 2414. THF was used as the mobile phase at a flow rate of $1.0 \mathrm{~mL} / \mathrm{min}$.

\subsection{Membrane Preparation and Performance}

Membranes for separation tests were prepared by solution casting and the solvent evaporation technique. PMMA-b-PDMAEA aqueous solutions of $8 w t \%$ were prepared. Then the solution was filtered to remove any undissolved suspend matters. The cast solution used for casting the membranes was de-foamed in the vacuum. The membrane was prepared by casting the polymer solution on polysulfone ultrafiltration membrane, the PSF support membrane was previously rinsed with dilute $\mathrm{NaOH}$ solution and flushed with deionized water to remove any possible contaminants from supplier before use, followed by evaporation at room temperature for more than 24 hours.

The permeation testing set-up used were similar to reported previously. The effective area of the tested composite membrane is $19.6 \mathrm{~cm}^{2}$. The obtained membrane was tested by feed gas which was pure gas of $\mathrm{CO}_{2}$ and $\mathrm{N}_{2}$. The permeation rate of the gas was calculated from the flow rate of $\mathrm{H}_{2}$ which is the sweep gas and the integral area of the penetrate gas, $\mathrm{CO}_{2}$ and $\mathrm{N}_{2}$, from the gas chromatograph with a thermal conductivity detector. The permeation rate and the selectivity are given by $\mathrm{R}_{\mathrm{i}}=\mathrm{N}_{\mathrm{i}} / \Delta \mathrm{pi}, \quad \mathrm{S}_{\mathrm{CO} 2 /}$ ${ }_{N} 2=R_{\text {CO2/RN2 }}$. Where $N_{i}$ is the permeation flux of permeate gas, $\Delta p_{i}$ is the trans-membrane partial pressure difference. $R_{\mathrm{CO} 2}, R_{\mathrm{N} 2}$ are the permeation rate of $\mathrm{CO}_{2}$ and $\mathrm{N}_{2}$, respectively.

\section{RESULTS AND DISCUSSIONS}

\subsection{RAFT Polymerization of MMA Using Disulfide Compounds as a Source of CTA}

According to the RAFT polymerization mechanism, the success of the RAFT polymerization of a particular monomer depends on R group's structure of a CTA [31]. The RAFT polymerizations of MMA with MTTCD, DBTTC and CPDB as RAFT agent and AIBN initiator, 
Table 1: RAFT Polymerization Results of MMA in the Presence of MTTCD, BDATC, CPDB

\begin{tabular}{|c|c|c|c|c|c|c|c|}
\hline Numbers & RAFT agents & Time(h) & $M / R / I$ & Conversion & $M_{n}^{a}(G P C)$ & $M_{n}^{b}$ (theoretical) & $M_{w} / M_{n}$ \\
\hline 1 & MTTCD & 10 & $150: 3: 1$ & $59.5 \%$ & 8052 & 3338 & 1.77 \\
\hline 2 & MTTCD & 10 & $300: 3: 1$ & $75.2 \%$ & 11463 & 7883 & 1.66 \\
\hline 3 & BDATC & 10 & $300: 3: 1$ & $50.0 \%$ & 20551 & 5282 & 1.43 \\
\hline 4 & BDATC & 6 & $300: 3: 1$ & $21.7 \%$ & 16903 & 2167 & 1.33 \\
\hline 5 & BDATC & 5 & $300: 3: 1$ & $35.7 \%$ & 8196 & 3852 & 1.26 \\
\hline 6 & BDATC & 5 & $600: 3: 1$ & $44.4 \%$ & 13933 & 9162 & 1.30 \\
\hline 7 & BDATC & 3 & $600: 3: 1$ & $11.3 \%$ & 7680 & 2542 & 1.27 \\
\hline 8 & BDATC & 3 & $50: 3: 1$ & $15.2 \%$ & 4836 & 532 & 1.25 \\
\hline 9 & CPDB & 10 & $900: 3: 1$ & $19.9 \%$ & 53539 & 6214 & 1.67 \\
\hline 10 & CPDB & 10 & $1500: 3: 1$ & $49.2 \%$ & 96592 & 24827 & 1.66 \\
\hline
\end{tabular}

${ }^{a} \mathrm{Mn}$ value measured by GPC is larger than the true value as reported. ${ }^{b}$ computed by equation: $M_{n}($ th $)=M_{\text {RAFT }}+n \cdot C o n v \cdot M_{M M A} \cdot$ Reaction temperature $70^{\circ} \mathrm{C}$.

respectively, were carried out. The conditions and results are listed in Table 1. When MMA was polymerized in the absence of MTTCD and CPDB (entry 1-2, 9-10). The resultant PMMA has a polydispersity indice $(\mathrm{PDI})>1.50$. The reason for this phenomenon maybe not only the CTA, but also the chain transfer ability which doesn't match with the activity of monomer. These PMMA chains are inactive macro RAFT agents which may also come from the polymerization process or from suboptimal purification. However, the polymerization of MMA in the presence of BDATC (entries 3-8 in Table 1) showed that the relative molecular mass of polymer was controllable. The polymer obtained was narrow in polydispersity index (< 1.5) and low monomer conversions. The polymerization is controlled for low ratios ([MMA]:[CTA]). At higher ratios, the polymerization is plagued by transferring to solvent. The contribution of transferring to solvent could have been attenuated by polymerizing at higher monomer concentration, but at such concentration, the increase of viscosity will result in a loss of control and broad PDls [32]. On the other hand, in any [MMA]:[CTA] ratios, the polymer molecular weight is above the theoretical molecular weight, because the first transferring between CTA and a propagating radical is less efficient than the subsequent transferring between a dormant chain and a propagating radical [33].

\subsection{Polymerization of MMA at Different Temperatures}

The effect of the polymerization temperature on the rate of the RAFT solution polymerization of MMA with AIBN as an initiator and BDATC as a RAFT agent was investigated, and the results are shown in Figure 1 and
Table 2. As shown in Figure 1, the corresponding plots of $\ln \left([\mathrm{M}]_{0} /[\mathrm{M}]\right)$ versus the polymerization time (where $[\mathrm{M}]_{0}$ is the initial monomer concentration and $[\mathrm{M}]$ is the monomer concentration) are nearly linear for all the polymerization temperatures $\left(70{ }^{\circ} \mathrm{C}\right.$ and $\left.80^{\circ} \mathrm{C}\right)$, which indicates that the radical concentrations were constant during the reactions. It also can be seen that the polymerization rate increased significantly with increasing polymerization temperature, which can be attributed to the fact that AIBN decomposes more quickly at a higher polymerization temperature than at a lower one. As shown in Table 2, The molecular weight distributions are relatively narrow (all of $M_{w} / M_{n}<$ 1.31) at different temperatures. However, the value of $\mathrm{Mn}(\mathrm{GPC})$ decreases as the increase in temperature

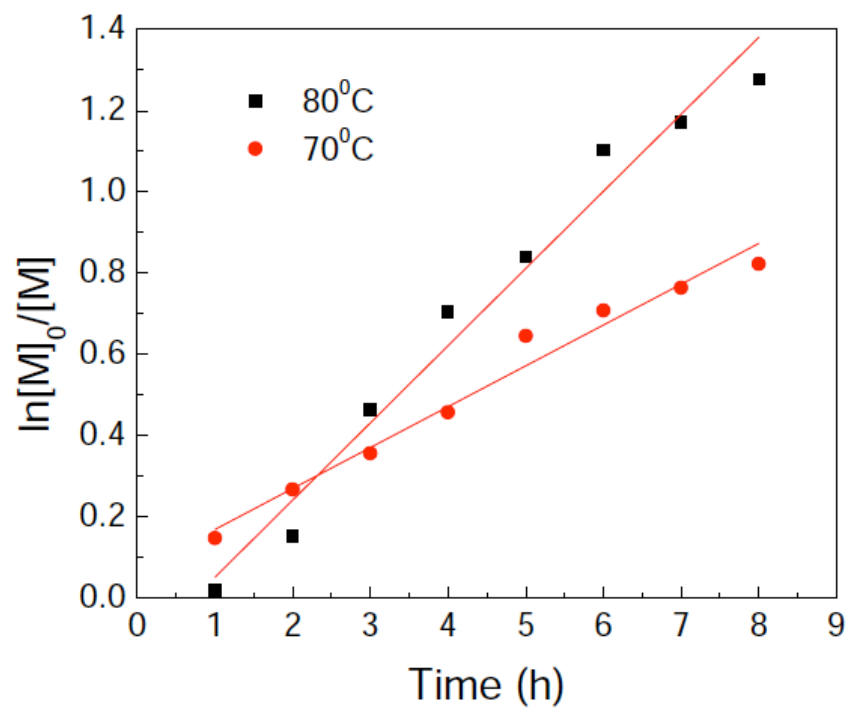

Figure 1: The pseudo-first-order kinetic plots(circles) for the polymerization of MMA with BDATC in the presence of AIBN in 1,4-dixoane at $70{ }^{\circ} \mathrm{C}, 80^{\circ} \mathrm{C}$ using a $[\mathrm{MMA}]_{0} /[\mathrm{BDATC}]_{0} /$ $[\mathrm{AIBN}]_{0}=300: 1: 0.33$. 
Table 2: The polymerization of MMA at Different Reaction Temperature, $[M M A]_{0} /[B D A T C]_{0} /[A \mid B N]_{0}=50: 3: 1$

\begin{tabular}{|c|c|c|c|c|c|}
\hline Numbers & Temperature $\left({ }^{\circ} \mathbf{C}\right)$ & Time $(\mathbf{h})$ & $\mathbf{M}_{\mathbf{n}}(\mathbf{G P C})$ & $\mathbf{M}_{\mathrm{n}, \mathrm{th}}$ (theoretical) & $\mathbf{M}_{\mathbf{w}} / \mathbf{M}_{\mathbf{n}}$ \\
\hline \hline 1 & 65 & 3 & 4625 & 449 & 532 \\
\hline 2 & 70 & 3 & 4836 & 614 & 1.25 \\
\hline 3 & 75 & 3 & 4595 & 1.27 \\
\hline 4 & 80 & 3 & 4483 & 1.30 \\
\hline
\end{tabular}

from $70{ }^{\circ} \mathrm{C}$ to $80{ }^{\circ} \mathrm{C}$, which is not agreement with the traditional theory. The reason maybe is the concentration of free radicals and free radical chains is very high in the polymerization system when at the high temperature, but the reaction time is short (only $3 \mathrm{~h}$ )so that there is no enough time for chains to propagate.

\subsection{Polymerization of MMA in the Presence of MTTCD}

Figures 2 and 3 show the plot of monomer conversion and $\ln \left([\mathrm{M}]_{0} /[\mathrm{M}]\right)$ versus reaction time for polymerization of MMA by RAFT using MTTCD as transfer agent in 1, 4-dixoane at $65^{\circ} \mathrm{C}$. The plot is approximately linear, which indicates that the system is in a stationary state with respect to the ratio $(\mathrm{Rp} /[\mathrm{M}]=$ $\mathrm{Kp}[\mathrm{P} \cdot])[34]$.

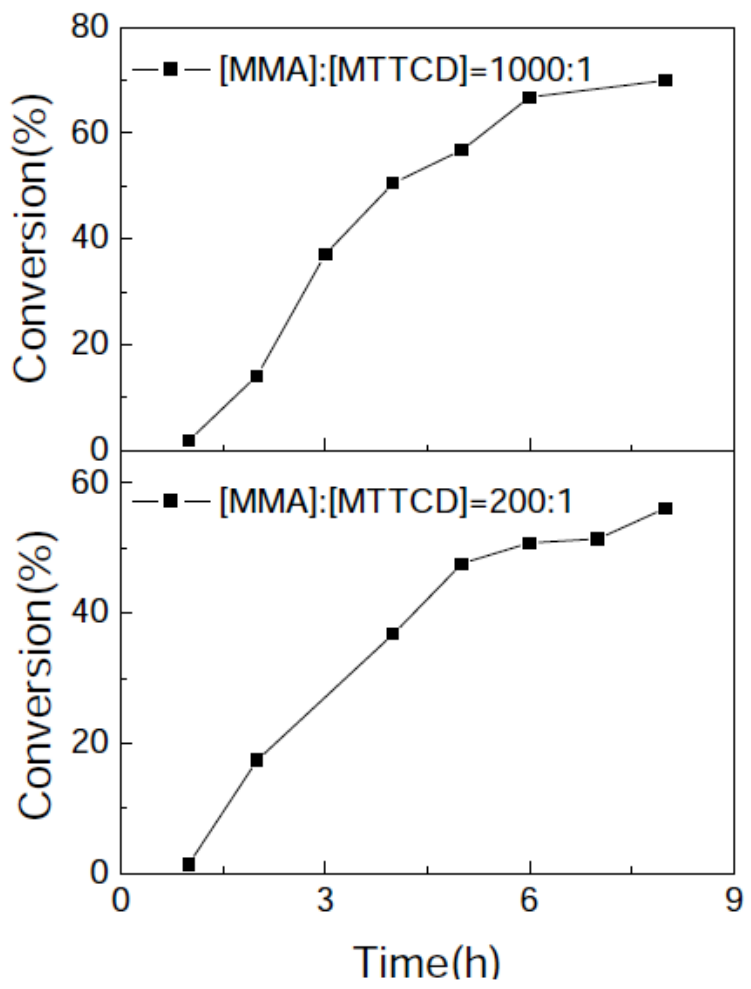

Figure 2: Conversion as a function of reaction time for polymerization of MMA by RAFT at $65{ }^{\circ} \mathrm{C},[\mathrm{MMA}]=3.3 \mathrm{~mol} / \mathrm{L}$, $[\mathrm{MTTCD}]:[\mathrm{AIBN}]=3: 1$.

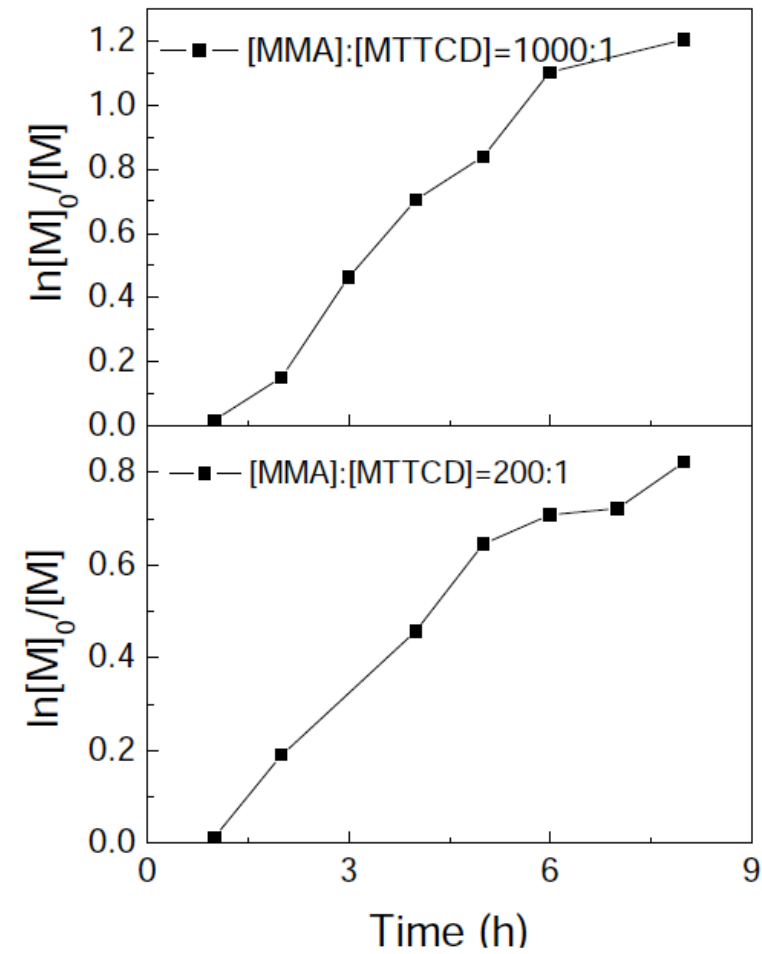

Figure 3: First-order kinetic plot of $\ln \left([M]_{0} /[M]\right)$ as a function of reaction time for polymerization of MMA by RAFT at $65^{\circ} \mathrm{C}$, $[\mathrm{MMA}]=3.3 \mathrm{~mol} / \mathrm{L},[\mathrm{MTTCD}]:[\mathrm{AIBN}]=3: 1$.

\subsection{Polymerization of MMA in the Presence of CPDB}

The polymerization of MMA with AIBN in the presence of CPDB in 1, 4-dixoane at $65{ }^{\circ} \mathrm{C}$ was investigated at a monomer/CTA/initiator molar ratio, $[\mathrm{MMA}]_{0} /[\mathrm{CPDB}]_{0} /[\mathrm{AIBN}]_{0}=500: 1: 0.33$. The timeconversion and the pseudo first-order kinetic plots are shown in Figure 4. The linearity of the pseudo firstorder kinetic plot suggests that there is a constant radical concentration throughout the RAFT polymerization and the polymerization occurs in a controlled manner.

\subsection{Synthesis of PMMA-b-PDMAEMA and PMMA-b- PDMAEA Block Polymers}

With the polymer capped by the dithioester moiety, the PMMA-b-PDMAEMA and PMMA-b-PDMAEA 


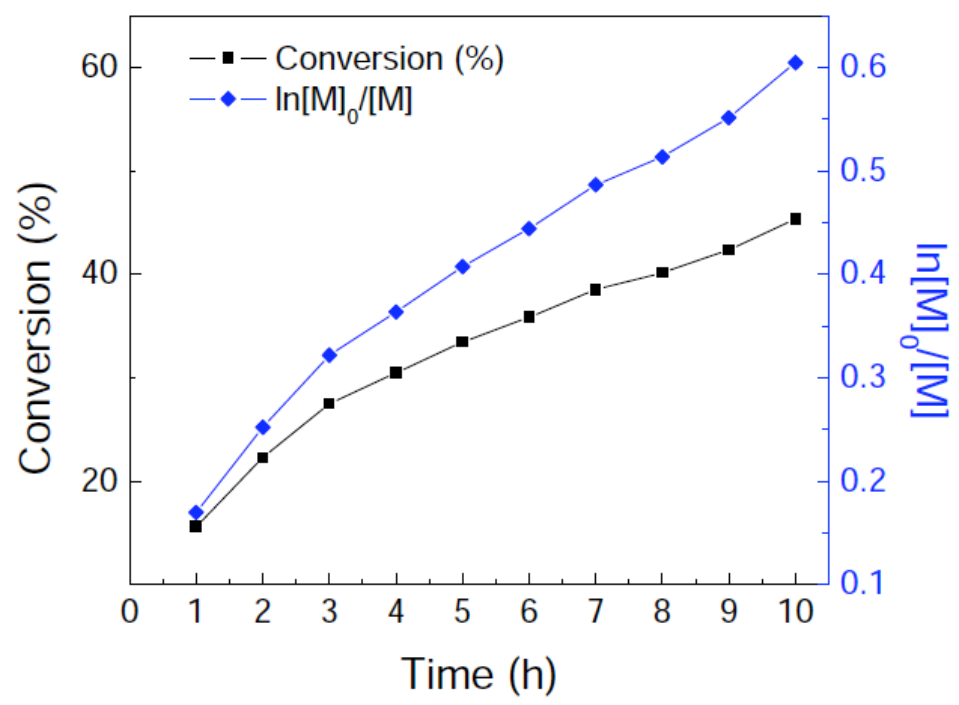

Figure 4: Time-conversion (squares) and The pseudo-first-order kinetic plots(circles) for the polymerization of MMA with CPDB in the presence of AIBN in 1,4 -dixoane at $65^{\circ} \mathrm{C}$ using a $[\mathrm{MMA}]_{0} /[\mathrm{CPDB}]_{0} /[\mathrm{AIBN}]_{0}=500: 1: 0.33$.

diblock polymers were synthesized with the original polymers (number-average molecular weight $\left(\mathrm{M}_{\mathrm{n}}=\right.$ 13350) as the macro-RAFT agents with a $[\mathrm{DMAEMA}]_{0} /[\mathrm{PMMA}] /[\mathrm{AIBN}]_{0}$ molar ratio and $[D M A E A]_{0} /[P M M A-C T A] /[A I B N]_{0}$ molar ratio(300:3:1, $500: 3: 1,900: 3: 1$ ) in 1, 4-dixoane (monomer/1, 4dixoane $=1: 2 \mathrm{v} / \mathrm{v})$ at $70{ }^{\circ} \mathrm{C}$, respectively. The polymerization of all monomers was well-controlled, in good agreement with theoretical molecular weights, and produced low PDI polymers. As an example, the effect of the Macro-RAFT of MMA with AIBN as an initiator and DMAEA as a second monomer was investigated, and the results are shown in Table 3 . The molecular weight distributions are relatively narrow (all of $M_{w} / M_{n}<1.3$ ) in all cases, which indicates that the original polymer is active. All these results show that these BDATC is effective controlling agent for the RAFT polymerization of MMA and DMAEA.

\subsection{IR Analysis}

Figure 5 shows FTIR spectra of block copolymer PMMA-b-PDMAEMA (Spectrum a) and PMMA homopolymer (Spectrum b). As illustrated in Figure 5, the FTIR spectra of the PMMA contains the characteristic band for $\mathrm{C}=\mathrm{O}$ stretching $(v=1730.8$ $\left.\mathrm{cm}^{-1}\right)$ and C-O stretching $\left(v=1149.0 \mathrm{~cm}^{-1}\right)$. On the other hand, there are three strong absorption peaks around $2900 \mathrm{~cm}^{-1}$ attributed to the stretching vibrations of $-\mathrm{CH}_{3}$ and $-\mathrm{CH}_{2}-$ groups. The absorption peak at $1064.5 \mathrm{~cm}^{-1}$ is the typical stretching vibrations of $\mathrm{C}=\mathrm{S}$ groups in CTA. The result of FT-TR indicates that PMMA is obtained and can be reacted as Macro-RAFT agent. The FTIR spectra of the PMMA-b-PDMAEMA contains the characteristic band for $\mathrm{O}-\mathrm{C}=\mathrm{O}$ stretching $\left(v=1730.8 \mathrm{~cm}^{-1}\right)$, associated with the -COOC groups of the blocked PMMA side chains, otherwise, it has been found that the absorption peak of tertiary amine at $1102 \mathrm{~cm}^{-1}$.

\section{7. ${ }^{1} \mathrm{H}$ NMR Characterization}

The ${ }^{1}$ HNMR spectrums of homopolymer PMMA and copolymer PMMA-b-PDMAEMA are shown in Figure 6. It is evident that the peaks appear between 7.27 and $7.90 \mathrm{ppm}$ which are assigned to the protons of phenyl. Some peaks between 1.33 and $2.12 \mathrm{ppm}$ are relative to the methylene protons of main chains. The two singals around $1.0 \mathrm{ppm}$ are assigned to the methyl group. The signal at $3.6 \mathrm{ppm}$ corresponds to the methyl protons of

Table 3: RAFT polymerization Results of DMAEA in the Presence of PMMA-CTA

\begin{tabular}{|c|c|c|c|c|c|c|c|}
\hline $\begin{array}{c}\text { Reaction } \\
\text { condition }\end{array}$ & $\begin{array}{c}\text { PMMA- } \\
\text { RAFT } \\
\mathbf{( g )}\end{array}$ & DMAEA (mI) & $\begin{array}{c}\text { Initiator } \\
\text { AIBN(g) }\end{array}$ & $\begin{array}{c}\text { Solvent 1,4- } \\
\text { dioxane(mI) }\end{array}$ & $\begin{array}{c}\text { [M]:[PMM- } \\
\text { RAFT]:[AIBN] }\end{array}$ & [M]:Solvent & $\mathbf{M}_{\mathbf{w}} / \mathbf{M}_{\mathbf{n}}$ \\
\hline \hline \multirow{2}{*}{$70^{\circ} \mathrm{C}, 10 \mathrm{~h}$} & 0.628 & 0.5 & 0.00164 & 25 & $300: 3: 1$ & $1: 2$ \\
\cline { 2 - 8 } & 0.628 & 0.833 & 0.00164 & 25 & $500: 3: 1$ & $1: 2$ & 1.22 \\
\cline { 2 - 8 } & 0.628 & 1.5 & 0.0667 & 17.5 & $900: 3: 1$ & $1: 2$ \\
\hline
\end{tabular}




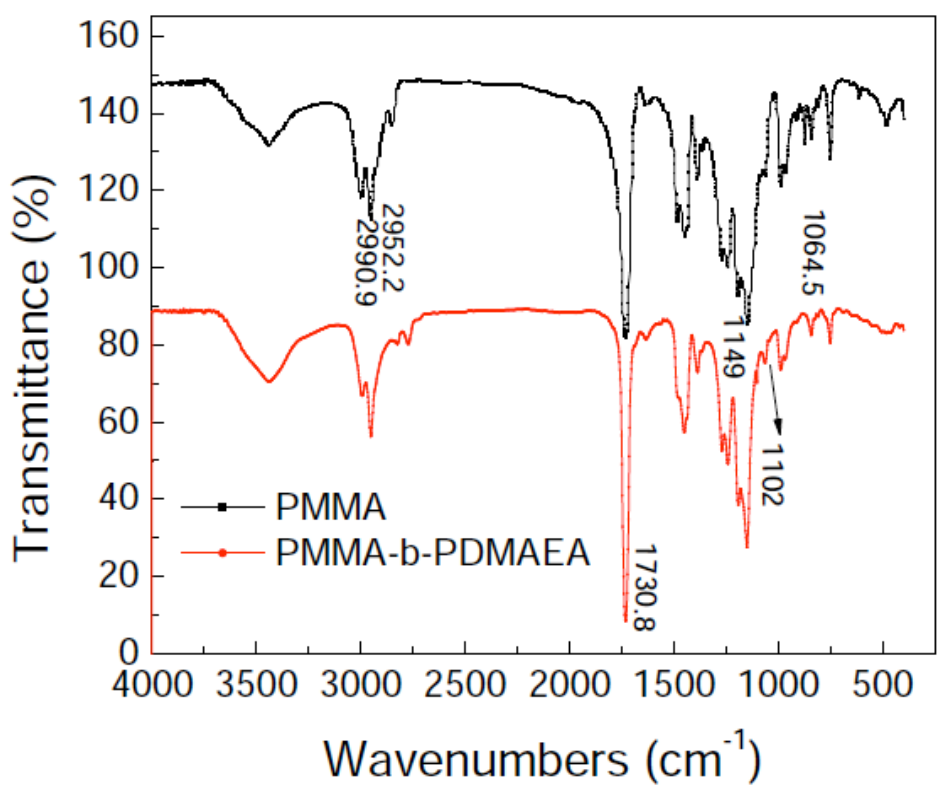

Figure 5: FTIR spectra of PMMA and PMMA-b-PDMAEA.

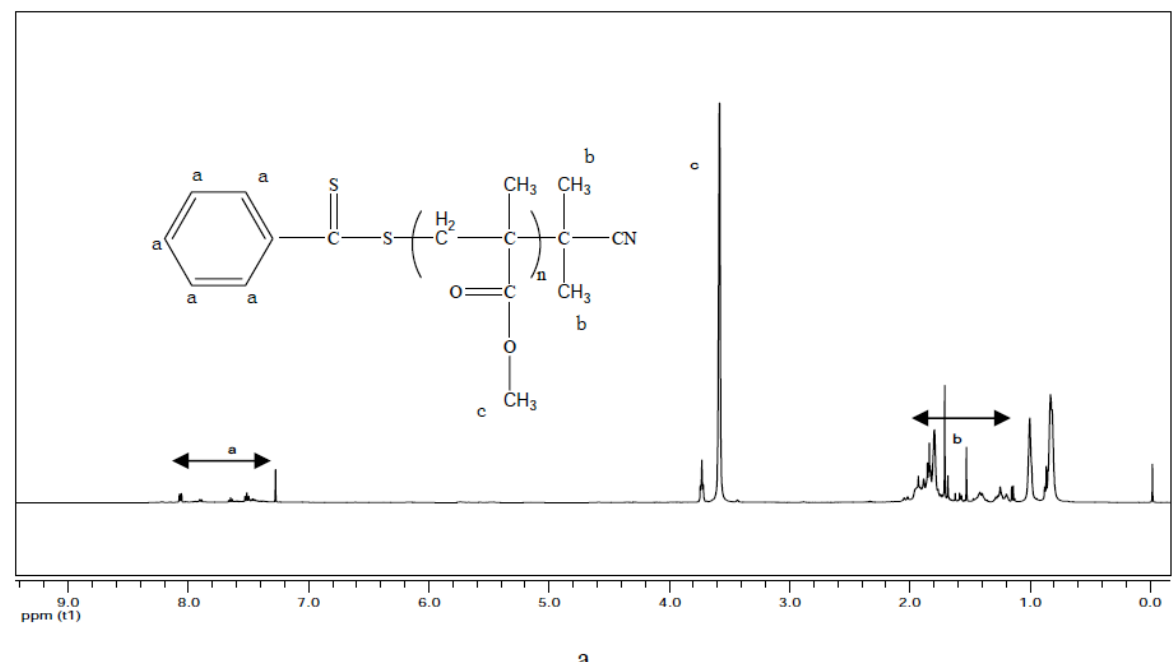

a

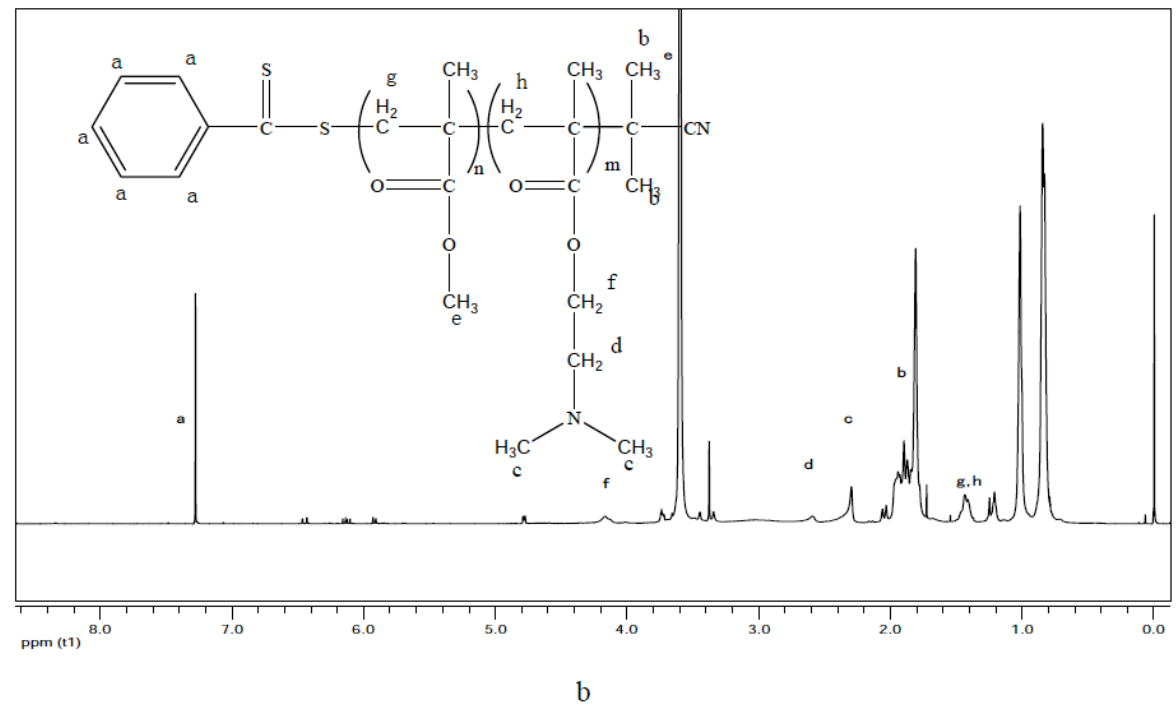

Figure 6: ${ }^{1} \mathrm{H}$ NMR spectra of the diblock polymers: (a) PMMA-CTA and (b) PMMA-b-PDMAEMA. 
methoxyl group. The chemical shifts at $2.36 \mathrm{ppm}$ (c) and $4.1 \mathrm{ppm}(\mathrm{f})$ can be assigned, respectively, to the methylene protons $\left(-\mathrm{NCH}_{2}-\right)$ and $\left(-\mathrm{OCH}_{2}-\right)$ of the PDMAEMA side chain. All of the results indicate that the copolymer is successfully synthesized.

\subsection{DSC Analysis}

Thermal property of the polymers was evaluated by differential scanning calorimetry (DSC). The DSC heating curves of the homopolymers PMMA, PDMAEMA and copolymer PMMA-b-PDMAEMA were given in Figure 7. The results showed typical glass transition temperatures $(\mathrm{Tg})$ of homopolymer PMMA and PDMAEMA at $48.4{ }^{\circ} \mathrm{C}$ and $32.6{ }^{\circ} \mathrm{C}$, respectively. Although PMMA and PDMAEMA are immiscible [35], there is only one glass transition point showed in block copolymer at $33.5{ }^{\circ} \mathrm{C}$ which was between that of precursor homopolymer PMMA and PDMAEMA. The reason may be due to the low molecular weight of PMMA and PDMAEMA in the block copolymer [36]. No obvious phase separation occurs in current block copolymer.

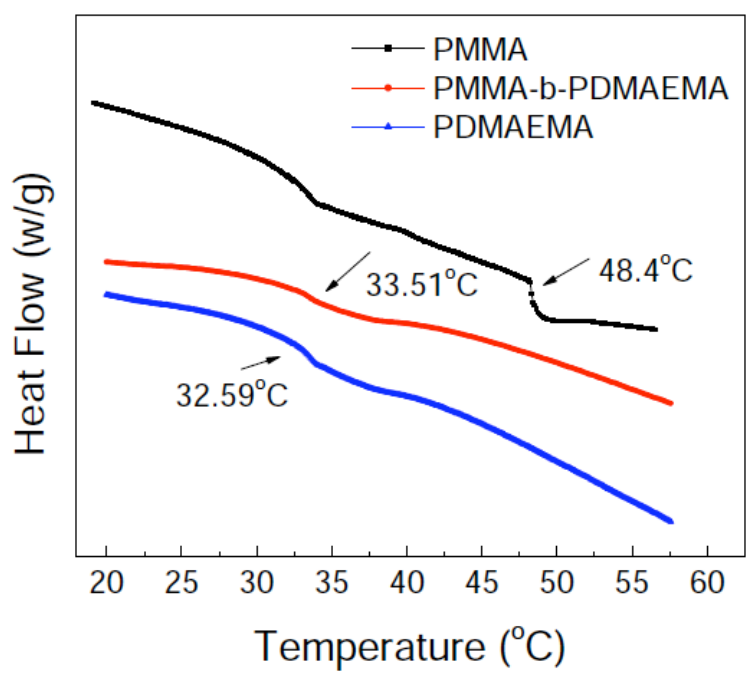

Figure 7: The DSC traces of the PMMA, PMMA-bPDMAEMA.

\subsection{XRD Analysis}

XRD traces of the PMMA-CTA and PMMA-bPDMAEMA are shown in Figure 8. The diffraction peak of PMMA-CTA and PMMA-b-PDMAEMA are formed by amorphous diffuse peak, which suggesting that they are completely amorphous polymers.

\subsection{Size Exclusion Chromatography (SEC)}

Molecular weight and PDI measurement methods were carefully assessed because of their critical nature

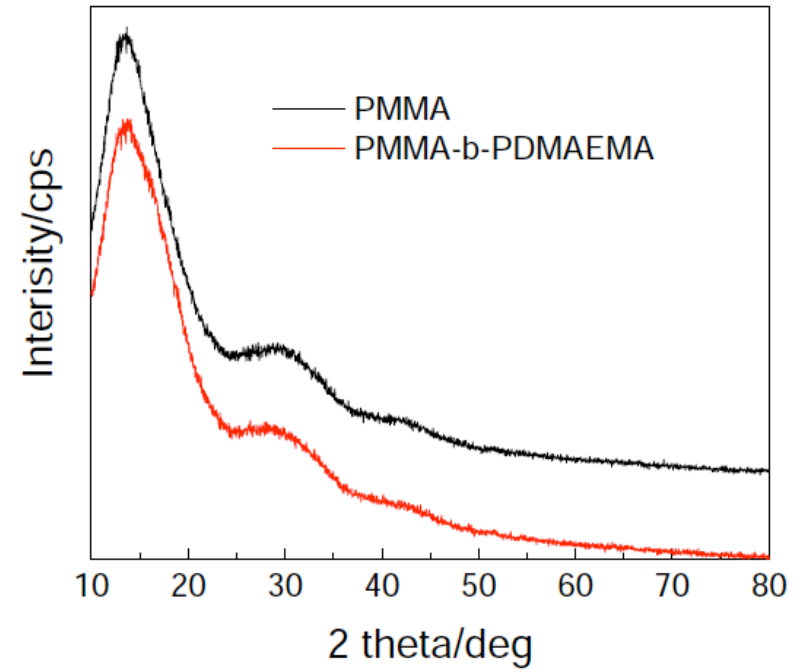

Figure 8: The XRD traces of the PMMA, PMMA-bPDMAEMA.

to the rest of this work. SEC traces of the PMMA macro RAFT agent and PMMA-b-PDMAEA block copolymers after dialysis are shown in Figure 9. DMAEA was polymerized in the presence of a PMMA macro-CTA. A clear shift of the GPC peak toward short elution time indicates that the chain extension has occurred. The SEC chromatogram of the chain extension of PMMA with DMAEA indicates near-quantitative blocking efficiency with the resulted diblocking copolymers having narrow, unimodal molecular weight distributions [37]. The inexistence of a new peak or a shoulder in the GPC curve shows that there is no homo-PDMAEMA.

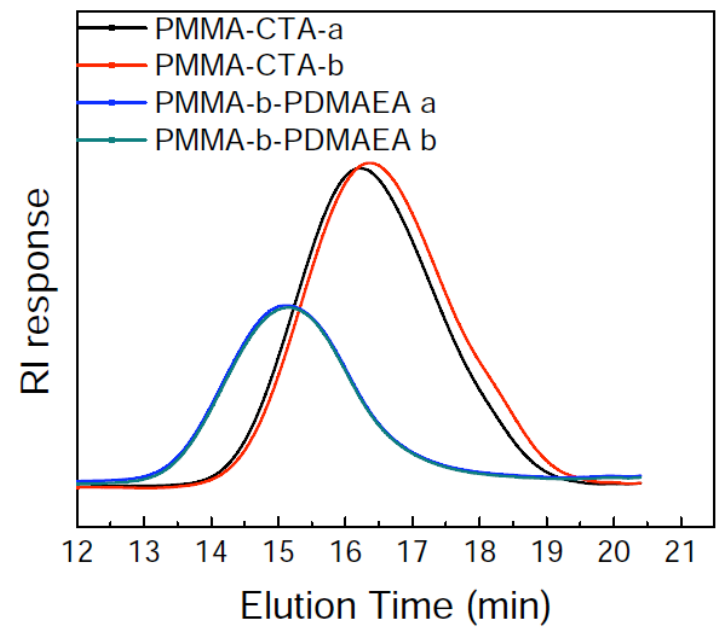

Figure 9: The GPC traces of the PMMA, PMMA-b-PDMAEA.

\section{4. $\mathrm{CO}_{2}$ SEPARATION PERFORMANCE OF PMMA-B- PDMAEA/PS COMPOSITE MEMBRANES SYNTHESIZED BY RAFT}

Figure 10 shows performance of the PMMA-bPDMAEA/PS composite membrane in different 


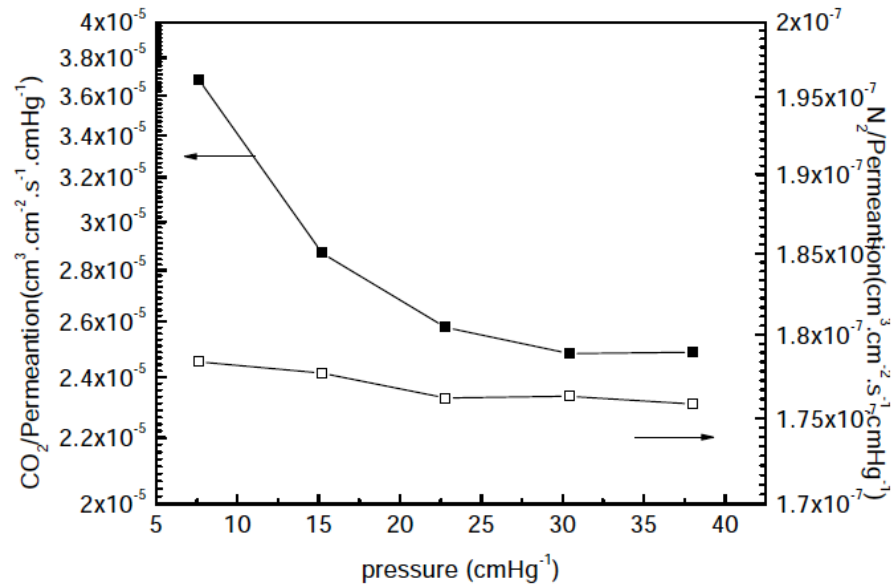

a

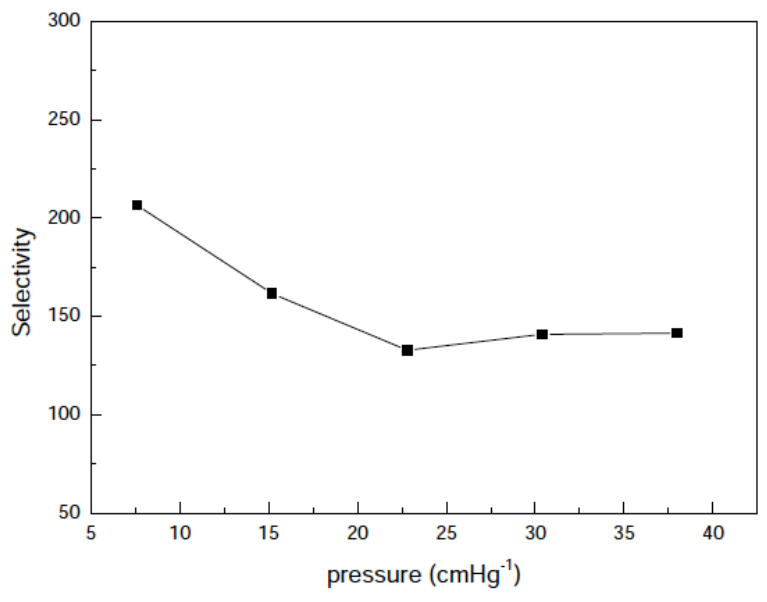

b

Figure 10: Performance of the PMMA-b-PDMAEMA/PS composite membrane in different pressure (a) $\mathrm{CO}_{2}$ and $\mathrm{N}_{2}$ permeation rate (b) Ideal selectivity of $\mathrm{CO}_{2}$ over $\mathrm{N}_{2}$ (Test temperature $30^{\circ} \mathrm{C}$, pure gas).

pressure (a) $\mathrm{CO}_{2}$ and $\mathrm{N}_{2}$ permeation rate (b) selectivity of $\mathrm{CO}_{2}$ over $\mathrm{N}_{2}$. The figure shows that the $\mathrm{CO}_{2}$ gas permeation rate decreases while the feed gas pressure increases. It is due to the increscent pressure increases the concentration of $\mathrm{CO}_{2}$ in the membrane, which results in facilitated transport reversible reaction. The penetration rate of $\mathrm{N}_{2}$ changes unobviously when the feed gas pressure changes. This is because $\mathrm{N}_{2}$ follows the dissolution diffusion mechanism. The resulted composited membrane had a $\mathrm{CO}_{2}$ permeation rate of $3.68 \times 10^{-5} \mathrm{~cm}^{3}$ (STP) $\mathrm{cm}^{-2} \mathrm{~s}^{-1} \mathrm{cmHg}^{-1}$ and a $\mathrm{N}_{2}$ permeation rate of $1.78 \times 10^{-7} \mathrm{~cm}^{3}(\mathrm{STP}) \mathrm{cm}^{-2} \mathrm{~s}^{-1} \mathrm{cmHg}^{-1}$ and an ideal $\mathrm{CO}_{2} / \mathrm{N}_{2}$ selectivity of 206.6 at a feed gas pressure of $7.6 \mathrm{cmHg}$ and $30{ }^{\circ} \mathrm{C}$. Further investigation of experimental conditions on membrane performance and membrane stability will be done in our lab.

\section{CONCLUSION}

The RAFT (co)polymerization of MMA has been successfully carried out in the presence of MTTCD, BDATC and CPDB as the chain transfer agent with the purpose to synthesize PMMA-CTA. The results show that the structure of the end-group of RAFT agents had significant effects on the ability to control polymerization. The polymerization is controlled for low ratios ([MMA]:[CTA]). At higher ratios, the polymerization is plagued by transfer to solvent. BDATC is the effective reversible additionfragmentation chain transfer (RAFT) agent for the RAFT polymerization of MMA. The polymerization showed "living"/controlled characteristics. Reaction kinetics was pseudo first order and linear. Relative molecular mass of polymer was controllable. The polymer obtained was narrow in polydispersity index
$(<1.5)$. However, in the cases of MTTCD and CPDB, they are not efficient enough to control the polymerization of MMA. The obtained polymers have broad molecular weight distributions. The derived wellcontrolled block copolymer PMMA-b-PDMAEMA and PMMA-b-PDMAEA were successfully prepared by using the above obtained polymer as macromolecular RAFT agent and DMAEMA or DMAEA as the second monomer. The molecular weight distributions are relatively narrow (most of $M_{w} / M_{n}<1.3$ ). The PMMA-bPDMAEA/PS composite membranes were prepared. The $\mathrm{CO}_{2}$ and $\mathrm{N}_{2}$ permeation performance were tested at different pressure. The results showed that the resulted composited membrane had a $\mathrm{CO}_{2}$ permeation rate of $3.68 \times 10^{-5} \mathrm{~cm}^{3}$ (STP) $\mathrm{cm}^{-2} \mathrm{~s}^{-1} \mathrm{cmHg}^{-1}$ and a $\mathrm{N}_{2}$ permeation rate of $1.78 \times 10^{-7} \mathrm{~cm}^{3}$ (STP) $\mathrm{cm}^{-2} \mathrm{~s}^{-1} \mathrm{~cm} \mathrm{Hg}^{-1}$ and an ideal $\mathrm{CO}_{2} / \mathrm{N}_{2}$ selectivity of 206.6 at a feed gas pressure of $7.6 \mathrm{cmHg}$ and $30{ }^{\circ} \mathrm{C}$.

\section{ACKNOWLEDGEMENTS}

The authors are grateful for subsidy provided by the National Natural Science Foundation of China (No. 20906082)

\section{ABBREVIATIONS}

MMA = methyl methacrylate

RAFT $=$ Reversible addition fragmentation chain transfer

CTA = Chain transfer agent

AIBN $=2,2^{\prime}$-Azo-bis(isobutyronitrile) 
MTTCD = S-1-Dodecyl-S'-( $\alpha, \quad \alpha^{\prime}$-dimethyl- $\alpha$-acetic acid) trithiocarbonate

BDATC $=$ S,S'-bis

dimethylacrylate) trithiocarbonate

(2-hydroxyethyl-2'-

CPDB = 2-cyanoprop-2-yl dithiobenzoate

DMAEA $=\mathrm{N}, \mathrm{N}$-dimethylaminoethy acrylate

DMAEMA $=\mathrm{N}, \mathrm{N}$-dimethylaminoethyl methacrylate

$\mathrm{OZ}=$ 2-ethyl-2-oxazoline

TETA = trimethylene tetramine

TMC = hexane-soluble trimesoyl chloride

PES = polyethersulfone

PVP = polyvinylpyrrolidone

VSA-SA $=\mathrm{N}$-vinyl- $\mathrm{\gamma}$-sodium aminobutyrate-sodium acrylate copolymer

PVA $\quad=\operatorname{poly}($ vinyl alcohol $)$

PAA $\quad=$ Poly $($ acrylic acid $)$

AIBN = $2,2^{\prime}$-Azo-bis(isobutyronitrile)

FTIR = Fourier Transform infrared spectroscopy

${ }^{1} \mathrm{HNMR}={ }^{1}$ Nuclear Magnetic Resonance Spectroscopy

GPC = Gel Permeation chromatography

DSC = Differential Scanning Calorimetry

XRD $=$ X-ray diffraction

SEC = Size exclusion chromatograph

PDI = polydispersity indice

$\mathrm{M}_{\mathrm{n}} \quad$ = Number-average molecular weight

$\mathrm{M}_{\mathrm{w}} \quad=$ Weight-average molecular weight

$\mathrm{M} / \mathrm{R} / \mathrm{I}=$ = Monomer/RAFT agent/ Initiator

\section{REFERENCE}

[1] Kaghazchi T, Gorji AH. Mathematical Modelling of Co(2) Facilitated Transport through Liquid Membranes Containing Amines as Carrier. Can J Chem Eng 2008; 86: 1039-46. http://dx.doi.org/10.1002/cjce.20107
Matsuyama H, Terada A, Nakagawara T, Kitamura Y, Teramoto $\mathrm{M}$. Facilitated transport of $\mathrm{CO}_{2}$ through polyethylenimine/poly(vinyl alcohol) blend membrane. $J$ Membrane Sci 1999; 163: 221-7.

http://dx.doi.org/10.1016/S0376-7388(99)00183-0

[3] Zhang Y, Wang Z, Wang SC. Synthesis and characteristics of novel fixed carrier membrane for $\mathrm{CO}_{2}$ separation. Chem Lett 2002; 31: 430-1.

http://dx.doi.org/10.1246/cl.2002.430

[4] Shen JN, Qiu JH, Wu LG, Gao CJ. Facilitated transport of carbon dioxide through poly (2-N,N-dimethyl aminoethyl methacrylate-co-acrylic acid sodium) membrane. Sep Purif Technol 2006; 51: 345-51.

http://dx.doi.org/10.1016/j.seppur.2006.02.015

Kim MJ, Park YI, Youm KH, Lee KH. Facilitated transport of $\mathrm{CO}_{2}$ through ethylenediamine-fixed cation-exchange polysaccharide membranes. J Membrane Sci 2004; 245: 7986.

http://dx.doi.org/10.1016/j.memsci.2004.07.019

[6] Kang SW, Kim JH, Won J, Char K, Kang YS. Effect of amino acids in polymer/silver salt complex membranes on facilitated olefin transport. J Membrane Sci 2005; 248: 201-6. http://dx.doi.org/10.1016/j.memsci.2004.08.028

[7] Zhao J, Wang Z, Wang JX, Wang SC. Influence of heattreatment on $\mathrm{CO}_{2}$ separation performance of novel fixed carrier composite membranes prepared by interfacial polymerization. J Membrane Sci 2006; 283: 346-56. http://dx.doi.org/10.1016/j.memsci.2006.07.004

[8] Zhang $\mathrm{Y}$, Wang Z, Wang SC. Facilitated transport of $\mathrm{CO}_{2}$ through synthetic polymeric membranes. Chinese $\mathrm{J}$ Chem Eng 2002;10: 570-4.

[9] Zhang $\mathrm{Y}$, Wang Z, Wang SC. Selective permeation of $\mathrm{CO}_{2}$ through new facilitated transport membranes. Desalination 2002; 145: 385-8. http://dx.doi.org/10.1016/S0011-9164(02)00441-1

[10] Yi CH, Wang Z, Li M, Wang JX, Wang SC. Facilitated transport of $\mathrm{CO}_{2}$ through polyvinylamine/polyethlene glycol blend membranes. Desalination 2006; 193: 90-6.

http://dx.doi.org/10.1016/j.desal.2005.04.139

[11] Shen JN, Wu LG, Chen HL, Gao CJ. Separation cyclohexene/cyclohexane mixtures with facilitated transport membrane of poly(vinyl alcohol)- $\mathrm{Co}^{2+}$. Sep Purif Technol 2005; 45: 103-8.

http://dx.doi.org/10.1016/j.seppur.2005.02.013

[12] Matsuyama $\mathrm{H}$, Teramoto $\mathrm{M}$, Matsui $\mathrm{K}$, Kitamura $\mathrm{Y}$. Preparation of poly(acrylic acid)/poly(vinyl alcohol) membrane for the facilitated transport of $\mathrm{CO}_{2}$. J Appl Polym Sci 2001; 81: 936-42. http://dx.doi.org/10.1002/app.1514

[13] Gaillard N, Claverie J, Guyot A. Synthesis and characterization of block-copolymer surfactants with specific interactions with associative thickeners. Prog Org Coat 2006; 57: 98-109.

http://dx.doi.org/10.1016/j.porgcoat.2006.05.006

[14] Gaillard N, Guyot A, Claverie J. Block copolymers of acrylic acid and butyl acrylate prepared by reversible additionfragmentation chain transfer polymerization: Synthesis, characterization, and use in emulsion polymerization. $J$ Polym Sci Pol Chem 2003; 41: 684-98. http://dx.doi.org/10.1002/pola.10606

[15] Garnier S, Laschewsky A. Synthesis of new amphiphilic diblock copolymers and their self-assembly in aqueous solution. Macromolecules 2005; 38: 7580-92. http://dx.doi.org/10.1021/ma0506785

[16] Chiefari J, Chong YK, Ercole F, et al. Living free-radical polymerization by reversible addition-fragmentation chain transfer: The RAFT process. Macromolecules 1998; 31 5559-62.

http://dx.doi.org/10.1021/ma9804951 
[17] Wang Y, Li X, Hong CY, Pan CY. Synthesis and Micellization of Thermoresponsive Galactose-Based Diblock Copolymers. J Polym Sci Pol Chem 2011; 49: 3280-90. http://dx.doi.org/10.1002/pola.24763

[18] Song XM, Zhang YQ, Yang D, et al. Convenient Synthesis of Thermo-Responsive PtBA-g-PPEGMEMA Well-Defined Amphiphilic Graft Copolymer Without Polymeric Functional Group Transformation. J Polym Sci Pol Chem 2011; 49: 3328-37.

http://dx.doi.org/10.1002/pola.24769

[19] Boisse S, Rieger J, Pembouong G, Beaunier P, Charleux B. Influence of the Stirring Speed and $\mathrm{CaCl}_{2}$ Concentration on the Nano-Object Morphologies Obtained via RAFT-Mediated Aqueous Emulsion Polymerization in the Presence of a Water-Soluble macroRAFT Agent. J Polym Sci Pol Chem 2011; 49: 3346-54. http://dx.doi.org/10.1002/pola.24771

[20] Mayadunne RTA, Rizzardo E, Chiefari J, et al. Living polymers by the use of trithiocarbonates as reversible addition-fragmentation chain transfer (RAFT) agents: ABA triblock copolymers by radical polymerization in two steps. Macromolecules 2000; 33: 243-5.

http://dx.doi.org/10.1021/ma991451a

[21] Mueller AHE, Schilli C, Lanzendoerfer M. Kinetic and MALDIToF MS investigation of the raft polymerization of $n$ isopropylacrylamide. Abstr Pap Am Chem S 2002; 224: 4756.

[22] Mayadunne RTA, Rizzardo E, Chiefari J, Chong YK, Moad $\mathrm{G}$, Thang $\mathrm{SH}$. Living radical polymerization with reversible addition-fragmentation chain transfer (RAFT polymerization) using dithiocarbamates as chain transfer agents. Macromolecules 1999; 32: 6977-80. http://dx.doi.org/10.1021/ma9906837

[23] Destarac M, Charmot D, Franck X, Zard SZ. Dithiocarbamates as universal reversible additionfragmentation chain transfer agents. Macromol Rapid Comm 2000; 21: 1035-9.

http://dx.doi.org/10.1002/1521-

3927(20001001)21:15<1035::AID-MARC1035>3.0.CO;2-5

[24] Hua DB, Zhang JX, Bai R, Lu WQ, Pan CY. Controlled/living free-radical polymerization in the presence of benzyl $9 \mathrm{H}$ carbazole-9-carbodithioate under (60)CO gamma-ray irradiation. Macromol Chem Phys 2004; 205: 1125-30. http://dx.doi.org/10.1002/macp.200300191

[25] Chiefari J, Mayadunne RTA, Moad CL, et al. Thiocarbonylthio compounds $(S=C(Z) S-R)$ in free radical polymerization with reversible addition-fragmentation chain transfer (RAFT polymerization). Effect of the activating group Z. Macromolecules 2003; 36: 2273-83. http://dx.doi.org/10.1021/ma020883+

[26] Chong YK, Krstina J, Le TPT, et al. Thiocarbonylthio compounds $[\mathrm{S}=\mathrm{C}(\mathrm{Ph}) \mathrm{S}-\mathrm{R}]$ in free radical polymerization with reversible addition-fragmentation chain transfer (RAFT polymerization): Role of the free-radical leaving group (R). Macromolecules 2003; 36: 2256-72.

http://dx.doi.org/10.1021/ma020882h
[27] Hua DB, Bai RK, Lu WQ, Pan CY. Dithiocarbamate mediated controlled/living free radical polymerization of methyl acrylate under Co-60 gamma-ray irradiation: Conjugation effect of $\mathrm{N}$ group. J Polym Sci Pol Chem 2004; 42: 5670-77.

http://dx.doi.org/10.1002/pola.20394

[28] Jitchum V, Perrier S. Living radical polymerization of isoprene via the RAFT process. Macromolecules 2007; 40: 1408-12.

http://dx.doi.org/10.1021/ma061889s

[29] Lai JT, Filla D, Shea R. Functional polymers from novel carboxyl-terminated trithiocarbonates as highly efficient RAFT agents. Macromolecules 2002; 35: 6754-6. http://dx.doi.org/10.1021/ma020362m

[30] Moad G, Chiefari J, Chong YK, et al. Living free radical polymerization with reversible addition-fragmentation chain transfer (the life of RAFT). Polym Int 2000; 49: 993-1001. http://dx.doi.org/10.1002/1097-0126(200009)49:9<993::AIDPI506>3.0.CO:2-6

[31] Smith AE, Xu XW, Mccormick CL. Stimuli-responsive amphiphilic (co)polymers via RAFT polymerization. Prog Polym Sci 2010; 35: 45-93.

http://dx.doi.org/10.1016/j.progpolymsci.2009.11.005

[32] Loiseau J, Doerr N, Suau JM, Egraz JB, Llauro MF, Ladaviere C. Synthesis and characterization of poly(acrylic acid) produced by RAFT polymerization. Application as a very efficient dispersant of $\mathrm{CaCO}_{3}$, kaolin, and $\mathrm{TiO}_{2}$. Macromolecules 2003; 36: 3066-77. http://dx.doi.org/10.1021/ma0256744

[33] Uzulina I, Kanagasabapathy S, Claverie J. Reversible addition fragmentation transfer (RAFT) polymerization in emulsion. Macromol Symp 2000; 150: 33-38. http://dx.doi.org/10.1002/1521-3900(200002)150:1<33::AIDMASY33>3.0.CO;2-C

[34] An QF, Qian JW, Yu LY, Luo YW, Liu XZ. Study on kinetics of controlled/living radical polymerization of acrylonitrile by RAFT technique. J Polym Sci Pol Chem 2005; 43: 1973-7. http://dx.doi.org/10.1002/pola.20622

[35] Huang XY, Huang ZH, Huang JL. Copolymerization of styrene and vinyl acetate by successive photoinduced charge-transfer polymerization. J Polym Sci Pol Chem 2000; 38: $914-20$

http://dx.doi.org/10.1002/(SICI)10990518(20000301)38:5<914::AID-POLA16>3.0.CO;2-K

[36] Xue XQ, Zhu JA, Zhang ZB, Cheng ZP, Tu YF, Zhu XL. Synthesis and characterization of azobenzene-functionalized poly(styrene)-b-poly(vinyl acetate) via the combination of RAFT and "click" chemistry. Polymer 2010; 51: 3083-90. http://dx.doi.org/10.1016/i.polymer.2010.04.052

[37] Donovan MS, Lowe AB, Sanford TA, McCormick CL. Sulfobetaine-containing diblock and triblock copolymers via reversible addition-fragmentation chain transfer polymerization in aqueous media. J Polym Sci Pol Chem 2003; 41: 1262-81.

http://dx.doi.org/10.1002/pola.10658

\section{DOI: http://dx.doi.org/10.6000/1929-6037.2012.01.02.6}

(C) 2012 Li et al.; Licensee Lifescience Global.

This is an open access article licensed under the terms of the Creative Commons Attribution Non-Commercial License (http://creativecommons.org/licenses/by-nc/3.0/) which permits unrestricted, non-commercial use, distribution and reproduction in any medium, provided the work is properly cited. 